\title{
Pre-Arrival Library Instruction for College Students
}

\begin{abstract}
Library instruction was given to University of New Hampshire freshmen before they reached the campus by means of a Freshman Handbook sent out in July 1964. Included also was a library competence quiz. A questionnaire administered after the students arrived showed that 78 per cent of those who received the Handbook read "The Library" section, that nearly all of this group took the test, and that many took steps to improve their library competence before coming to college.
\end{abstract}

$\mathrm{T}$ HE ENORMOUS TASK of introducing large numbers of new students to the library has been somewhat alleviated at the University of New Hampshire by mailing library instruction to incoming freshmen before they arrive on the campus. This device was tried with encouraging results with the class that entered in the fall of 1964. The instruction was part of a Freshman Handbook which introduced various campus services. Accompanying the Handbook was a library competence test to be corrected by the student. If his grade was low, it was suggested he improve his skill by visiting his local public library and by consulting books that would help him. The effectiveness of the instruction was tested by means of a short questionnaire after the students reached the campus.

The questionnaire revealed that 78 per cent of those who received the Handbook read "The Library" section, and almost all of them took the examination. It is interesting to note that few who received poor scores reported doing anything to improve their skill, but many others reported such action as "Spoke to a librarian," "Checked the wrong answers to see where I made er-

Mr. Pritchard is Reference Librarian in the University of New Hampshire. rors," "Read Cook's Library Key," ora more loquacious type-“On arriving at the university, I went to the library and, using some sample books, made myself familiar with the facilities here."

The test tested familiarity with $\mathrm{Li}$ brary of Congress catalog cards and the Readers' Guide to Periodical Literature. The number reporting perfect or near perfect scores was high and suggests that a more difficult test might not be out of order. A revised quiz should also test familiarity with several reference books, bibliographic terms, and simple rules of filing.

The instruction in the Handbook was divided into "Before You Arrive" and "Now That You Are Here." The first stressed the need to know how to use a library and suggested ways to improve one's skill. The second outlined library services and routines for finding and charging books. The questionnaire, an essential part of the program, consisted of seven short questions. It was administered by the freshman English instructors on the first day of class and was unsigned.

Samples of the questionnaire, the test and "The Library" section of the Handbook may be requested from the reference department of the University of New Hampshire library in Durham. 